\title{
Thermal Model of High-Speed Spindle Units
}

\author{
Jeong-Du Kim', Igor Zverv², Keon-Beom Lee ${ }^{3}$ \\ ${ }^{1}$ School of Mechanical Engineering, Sejong University, Seoul, South Korea \\ ${ }^{2}$ Crygenmash Co. Moscow, Russia \\ ${ }^{3}$ Department of Mechanical Engineering, Korea Polytechnic IV, Daejeon, South Korea \\ E-mail: jdkim@sejong.ac.kr \\ Received October 7, 2009; revised January 21, 2010; accepted March 8, 2010
}

\begin{abstract}
For the purpose to facilitate development of high-speed Spindle Units (SUs) running on rolling bearings, we have developed a beam element model, algorithms, and software for computer analysis of thermal characteristics of SUs. The thermal model incorporates a model of heat generation in rolling bearings, a model of heat transfer from bearings, and models for estimation of temperature and temperature deformations of SU elements. We have carried out experimental test and made quantitative evaluation of the effect of operation conditions on friction and thermal characteristics of the SUs of grinding and turning machines of typical structures. It is found that the operation conditions make stronger effect on SU temperatures when rpm increases. A comparison between the results of analysis and experiment proves their good mutual correspondence and allows us to recommend application of the models and software developed for design and research of high-speed SUs running on rolling bearings.
\end{abstract}

Keywords: Thermal Model, High-Speed, Spindle, Unit, Rolling Bearing

\section{Introduction}

SU thermal properties, besides the accuracy of rotation and static and dynamic stiffness, strongly affect the accuracy of machine tool. Heating of bearings caused by friction is one of the main factors limiting SU high-speed. Practical and analytical studies prove that when increasing rotational speed of $\mathrm{SU}$, friction losses in bearings increase to high values, and this should be estimated when choosing the bearing and drive types. Thus, for example, the estimated friction losses in the bearings of $\mathrm{SU}$ of lathe (spindle diameter $90 \mathrm{~mm}$ ) at $5,000 \mathrm{rpm}$ can reach $2.9 \mathrm{~kW}$ after temperature stabilization [1].

Modern requirements to SUs make it necessary to estimate quantitatively their thermal characteristics at early stage of development. Application of the well-known software complexes, such as I-DEAS, ANSYS, and NASTRAN, makes sense at final stage of designing, when details of structures are under consideration. The standard complexes based on application of Finite Element Method (FEM) facilitate simulation of SU geometry, but give no opportunity to consider specific peculiarities of SU structures (particularly, the type of bearing preloading) and conditions of operation (dependencies of SU heat transfer on rpm and temperature, viscosity of bearings' lubricant on temperature, etc.). Besides, the standard software does not incorporate the models for numerical estimation of heat generation in bearings, and require a lot of preparatory work before usage.

That is why, following the purpose to increase quality and efficiency of SU design process at early stage, we develop a thermal model of SU and specialized software intended for numerical express-evaluation of frictional and thermal characteristics of high-speed SUs in accounting for their structural and functional peculiarities [2]. In order to realize the model, we apply the universal beam element analytical diagrams of SUs for solution of the problems of statics, dynamics, and heat transfer of SUs (Figure 1).

Using the software developed, we obtain the numerical evaluations of the effect of operation parameters (rpm, external load, bearing preloads, parameters of lubricant, and heat transfer) on the friction and thermal characteristics of high-speed SUs of grinding and turning machines. We also perform an experimental study of friction and thermal characteristics of a SU of grinding machine using a special rig and the standard instruments. Comparison of the results of numerical and experimental studies obtained proves high efficiency of the model and software developed. 


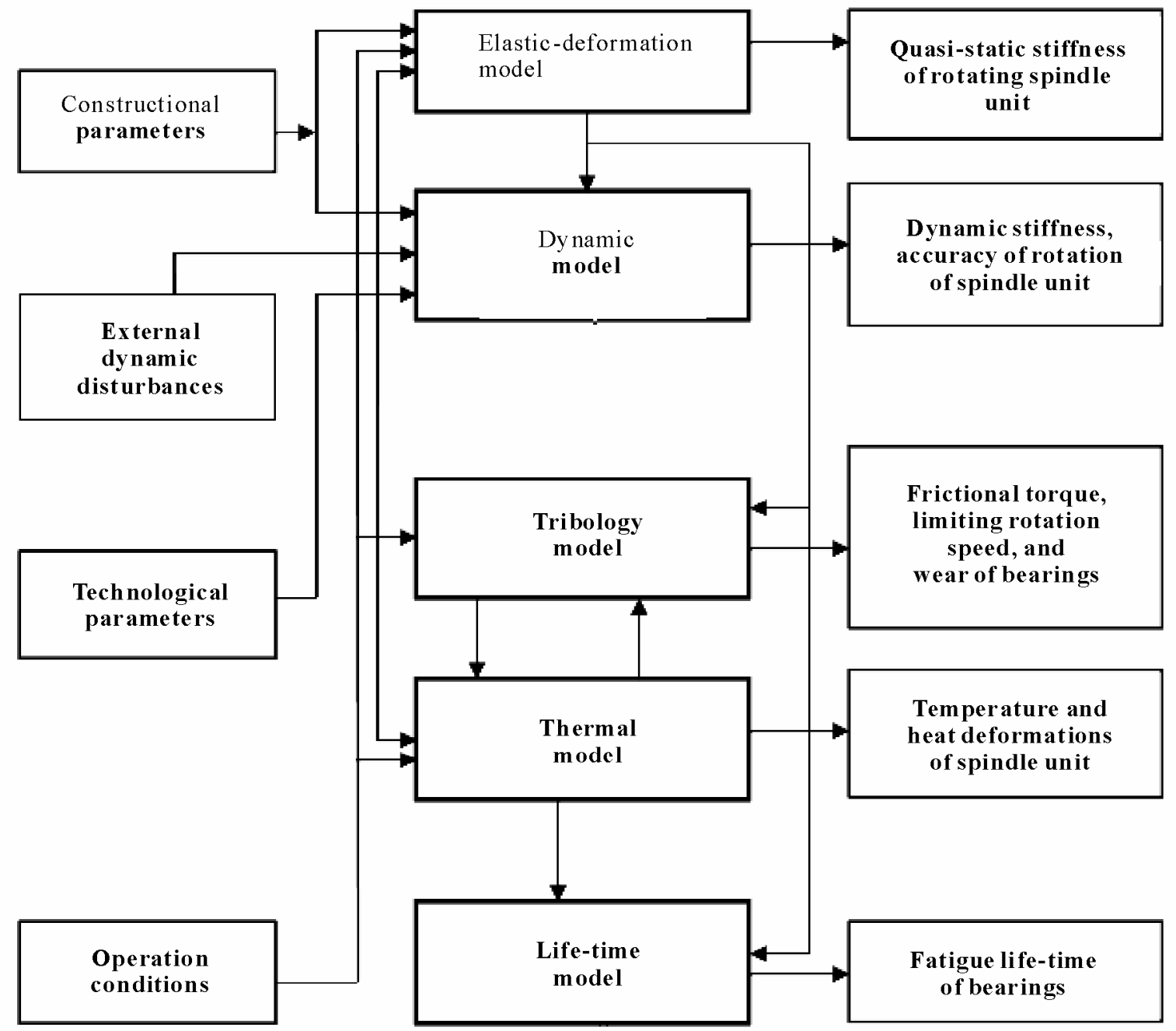

Figure 1. Diagram of the complex model of spindle units.

\section{Principle Statements of Thermal Analysis}

Thermal model of a system 'SU-external medium' presumes estimation of the following characteristics: friction losses (heat generation) in bearings; heat transfer from SU's surfaces; temperatures and temperature deformations of SU's elements.

\subsection{Assumptions and Conditions Used in Thermal Analysis}

When developing a thermal model of SU, we make the following assumptions:

1) The main source of heat generation in bearings is friction;
2) The heat generated in bearing distributes equally between inner and outer races;

3) The bearings are considered to be circular heat sources;

4) The temperatures of spindle and cylindrical housing are constant within structures' radial cross-sections.

When estimating heat generation in bearings and heat transfer from SU's elements, we assume that:

1) Heat generation in bearings can be determined by hydrodynamic and load components of friction; at that, the lubricant viscosity depends on bearing temperature;

2) Excessive heat dissipates by means of free and forced convective heat transfer and heat conductivity of SU's materials.

3) Thermal-physical parameters of heat transfer are the 
functions of temperature and rate of surface air-cooling;

4) Variations of clearance-tightness in bearings with temperature are the result of the differences of temperatures of SU's elements, conditions of heat transfer, and differences in the properties of materials of spindle and housing.

When developing analytical thermal diagram of SU, we use one-dimensional axial beam elements and radial ring elements. In Figure 2, we show the diagram of heat transfer and analytical diagram of SU mounted in bushtype casing.

In result of heat generation in bearing, its temperature increases up to the moment when the generated and transferred heat becomes equal. This condition is assumed to be a condition of heat balance (stationary heat exchange), and can be represented in the form of equation of heat balance:

$$
\mathrm{Q}_{\mathrm{B}}=\mathrm{Q}_{\mathrm{S}}+\mathrm{Q}_{\mathrm{H}}+\mathrm{Q}_{\mathrm{C}}
$$

where $\mathrm{Q}_{B}$ is the quantity of heat generated in bearing; $\mathrm{Q}_{\mathrm{S}}$ and $\mathrm{Q}_{\mathrm{H}}$ are the heat outputs provided by spindle and housing, respectively; $\mathrm{Q}_{\mathrm{C}}$ is the heat output provided by SU cooling system.

Heat generation in bearing can be determined as the function of friction losses for given conditions of SU operation:

$$
\mathrm{Q}_{\mathrm{B}}=\mathrm{Q}_{\mathrm{B}}\left(\mathrm{M}_{\mathrm{F}}, \mathrm{n}\right)
$$

where $\mathrm{M}_{\mathrm{F}}$ is the bearing friction torque; $\mathrm{n}$ is the spindle rpm.

Heat transfer from bearings takes place in axial direction along spindle and housing. Interaction of convection and radiation of heat can be estimated by the weighted average values of coefficients of heat transfer from SU's surfaces. Determination of the coefficients of heat transfer for particular conditions of SU operation makes the main difficulty of thermal analysis. The corresponding analytical dependencies of coefficients of heat transfer on temperature and rate of air-cooling of surfaces are presented in [3]. The linear dependencies of coefficients of heat conductivity of SU materials on temperature (in the temperature band $20-100^{\circ} \mathrm{C}$ ) can be obtained from the reference data presented in [3].

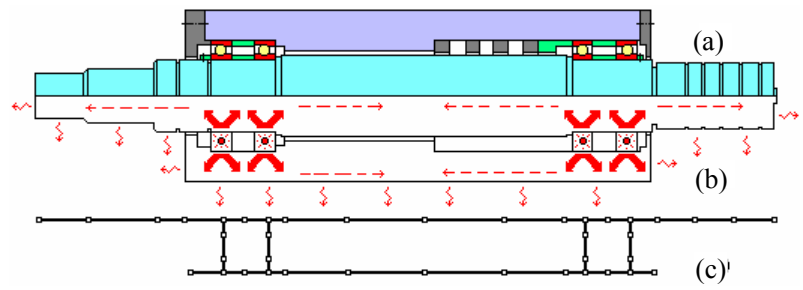

Figure 2. Structural (a) heat transfer; (b) analytical; (c) diagrams of the spindle unit.

\subsection{The Model of Heat Generation in Spindle Bearings}

Heat generation in bearings (friction losses) depends on many factors, estimation of which makes a complicated theoretical problem [4]. Since this problem is not solved, yet, we use the simplified engineering method by Palmgren [5], which gives us the following formula for bearing friction torque:

$$
\mathrm{M}_{\mathrm{F}}=\mathrm{M}_{0}+\mathrm{M}_{1}
$$

Here, $\mathrm{M}_{0}$ is the hydrodynamic component of friction torque, which does not depend on load, but depend on rpm; $M_{1}$ is the load dependent component, which does not depend on rpm.

The friction losses $\mathrm{N}_{\mathrm{F}}$ (in $\mathrm{W}$ ) equal to the power of heat generation $\mathrm{Q}_{\mathrm{B}}$ in bearing, we estimate by the formula:

$$
\mathrm{N}_{\mathrm{F}}=\mathrm{Q}_{\mathrm{B}}=1.047 \cdot 10^{-3} \cdot \mathrm{n} \cdot \mathrm{M}_{\mathrm{F}}
$$

where the hydrodynamic component of friction torque:

$$
\begin{gathered}
\mathrm{M}_{0}=10^{-7} \cdot \mathrm{f}_{0} \cdot(v \cdot \mathrm{n})^{2 / 3} \cdot \mathrm{d}_{\mathrm{m}}{ }^{3}(\text { if } v \cdot \mathrm{n} \geq 2000) ; \\
\mathrm{M}_{0}=160 \cdot 10^{-7} \cdot \mathrm{f}_{0} \cdot \mathrm{d}_{\mathrm{m}}{ }^{3}(\text { if } v \cdot \mathrm{n}<2000) .
\end{gathered}
$$

Here, $d_{m}$ is the averaged bearing diameter in $\mathrm{mm} ; v(\mathrm{~T})$ is the lubricant kinematic viscosity at the temperature $\mathrm{T}$ in cSt; $\mathrm{f}_{0}$ is the coefficient dependent on lubricant type (see Table 1).

The load dependent component of friction torque:

$$
\begin{gathered}
M_{1}=\mathrm{f}_{1} \cdot P \cdot\left(\frac{\mathrm{P}}{\mathrm{C}_{0}}\right)^{\mathrm{c}} \cdot \mathrm{d}_{\mathrm{m}} ; \text { (for ball bearings) } \\
\mathrm{M}_{1}=\mathrm{f}_{1} \cdot \mathrm{P} \cdot \mathrm{d}_{\mathrm{m}}, \text { (for roller bearings) }
\end{gathered}
$$

Here, $\mathrm{P}$ is the equivalent load applied to the bearing in $\mathrm{dN} ; \mathrm{C}_{0}$ is the bearing static load carrying capacity in $\mathrm{dN}$; $\mathrm{c}$ and $\mathrm{f}_{1}$ are the coefficients dependent on type of bearing and character of loading (see Table 1).

The equivalent load can be estimated as follows:

$$
\begin{gathered}
\mathrm{P}=0.9 \cdot \mathrm{P}_{\mathrm{a}} \cdot \operatorname{ctg}(\alpha)-0.1 \cdot \mathrm{P}_{\mathrm{r}} ;(\text { for ball bearings) }(9) \\
\mathrm{P}=0.8 \cdot \mathrm{P}_{\mathrm{a}} \cdot \operatorname{ctg}(\alpha) ; \text { for taper roller bearings) }(10) \\
\mathrm{P}=\mathrm{P}_{\mathrm{r}},(\text { for cylindrical roller bearings) }
\end{gathered}
$$

where, $\mathrm{P}_{\mathrm{a}}$ and $\mathrm{P}_{\mathrm{r}}$ are the axial and radial loads; $\alpha$ is the bearing contact angle.

In the case of double-row cylindrical roller bearing, we specify the friction losses by taking into account the bearing real clearance-tightness following the experimental results presented in [6]. For this purpose, we introduce the coefficient $k_{r}$ into the Formula (8), which takes into account the real radial clearance-tightness $\Delta_{\mathrm{r}}$ $(\mu \mathrm{m})$, which varies with temperature and depends on thermal deformations of bearing's elements: 
Table 1. Factors $\mathbf{f}_{0}, \mathbf{f}_{\mathbf{1}}$, and $\mathrm{c}$.

\begin{tabular}{|c|c|c|c|c|c|c|c|}
\hline \multirow[b]{2}{*}{ Bearings } & \multirow[b]{2}{*}{ Oil-Air } & \multicolumn{3}{|c|}{ Type of lubrication factor $f_{0}$} & \multirow[b]{2}{*}{ Oil-Drop } & \multirow{2}{*}{$\begin{array}{c}\begin{array}{c}\text { Bearing } \\
\text { loading } \\
\text { factor }\end{array} \\
\mathrm{f}_{1}\end{array}$} & \multirow{2}{*}{$\begin{array}{c}\text { Bearing } \\
\text { type factor } \\
\mathrm{c}\end{array}$} \\
\hline & & Grease & Oil- Injection & Oil-Circulation & & & \\
\hline $\begin{array}{l}\text { Double-row cylindrical } \\
\text { roller bearing }\end{array}$ & $1.5-3$ & $3-4$ & $6-10$ & $8-12$ & $2-4$ & 0.00025 & 0 \\
\hline $\begin{array}{l}\text { One-row taper roller } \\
\text { bearing }\end{array}$ & $1.5-2$ & $1.5-4$ & $6-8$ & $8-10$ & $1.5-3$ & 0.0005 & 0 \\
\hline $\begin{array}{l}\text { One-row angular ball } \\
\text { bearing }\end{array}$ & $0.7-1$ & $0.7-2$ & $3-4$ & $4-5$ & $0.7-1$ & 0.002 & 0.5 \\
\hline $\begin{array}{l}\text { Double-row angular } \\
\text { ball bearing }\end{array}$ & $1.4-2$ & $1.5-4$ & $6-8$ & $8-10$ & $1.4-2$ & 0.002 & 0.33 \\
\hline $\begin{array}{l}\text { Double-row taper roller } \\
\text { bearing }\end{array}$ & $3-4$ & $3-6$ & $12-16$ & $16-20$ & $3.5-6$ & 0.001 & 0 \\
\hline
\end{tabular}

$$
\begin{gathered}
\mathrm{k}_{\mathrm{r}}=2-10^{4} \cdot \frac{\Delta_{\mathrm{r}}}{\mathrm{d}_{\mathrm{s}}} ; \text { (clearance) } \\
\mathrm{k}_{\mathrm{r}}=0.26 \cdot\left(2+10^{4} \cdot \frac{\left|\Delta_{\mathrm{r}}\right|}{\mathrm{d}_{\mathrm{s}}}\right)^{3}, \text { (tightness) }
\end{gathered}
$$

where $\mathrm{d}_{\mathrm{s}}$ is the spindle's journal diameter in $\mathrm{mm}$.

Variation of hydrodynamic component of friction losses in bearing $\mathrm{M}_{0}$ depends on the coefficient $\mathrm{f}_{0}$. In order to facilitate engineering analysis, we propose to use the limiting values of $\mathrm{f}_{0}$ for different types of bearing lubrication (see Table 1), which we obtained by generalization of the results of different studies [4,7]. At low and moderate loads applied to $\mathrm{SU}$, the idle friction torque $\mathrm{M}_{0}$ makes the greatest part (up to $85-95 \%$ ) of the bearing total friction torque. However, the components $\mathrm{M}_{0}$ and $\mathrm{M}_{1}$ interfere, since when the load increases, an increase of the load component $\mathrm{M}_{1}$ brings to an increase of the temperature, which, in turn, causes a decrease of lubricant viscosity, and, thus, a decrease of the hydrodynamic component $\mathrm{M}_{0}$.

In practice, SU thermal characteristics can vary significantly, and this variation is caused by a number of factors effecting conditions of heat generation and transfer. Particularly, a significant effect makes the variations of lubricant viscosity and volume. When evaluating heat generation in bearings, we estimate the dependence of oil viscosity $v$ on temperature $T$ (for the temperature band $20-150^{\circ} \mathrm{C}$ using the following power dependence [3]:

$$
v(T)=v_{40} \cdot\left(\frac{40}{T}\right)^{\mathrm{m}},
$$

where $v_{40}$ is the kinematic viscosity (in cSt) at $40^{\circ} \mathrm{C}$; $\mathrm{m}$ is the exponent.

Following the results obtained in Russian Scientific
Research Institute for Machine Tools (ENIMS) [8] and applying the graphic 'viscosity - temperature' proposed by FAG Company [9], we can estimate the exponent ' $m$ ' by the formula:

$$
\mathrm{m}=\frac{\ln \left(\frac{v_{2}}{v_{1}}\right)}{\ln \left(\frac{\mathrm{T}_{1}}{\mathrm{~T}_{2}}\right)},
$$

where subscripts 1 and 2 denote the upper and lower values of temperature and viscosity of lubricant in the operation band, respectively.

\subsection{Equation of Heat Transfer and Solution Method}

A solution of the nonstationary problem of heat transfer can be derived by applying FEM and solving the system of linear differential equations in the matrix form [10]:

$$
\mathrm{C} \cdot \dot{\boldsymbol{T}}+\mathrm{H} \cdot T=Q(t),
$$

where $\mathrm{C}$ and $\mathrm{H}$ are the matrices of heat capacity and heat conductivity of SU; $T$ is the vector of unknown node temperatures; $Q$ is the vector of heat load; $t$ is time.

The matrices of heat capacity and heat conductivity, we represent as follows:

$$
\mathbf{C}=\sum_{\mathbf{e}=\mathbf{1}}^{p} \mathbf{C}_{\mathbf{e}} ; \quad \mathbf{H}=\sum_{\mathbf{e}=\mathbf{1}}^{p} \mathbf{H}_{\mathbf{e}},
$$

where $\mathrm{C}_{e}$ and $\mathrm{H}_{\mathrm{e}}$ are the local matrices of heat capacity and heat conductivity of the element ' $e$ '; ' $p$ ' is the number of elements in SU analytical diagram. For the axial beam type and radial elements (see Figure 2), we obtain the expressions for local matrices of heat conductivity and heat capacity using the general integrals of FEM [10]. Thus, for a beam type element, we have: 


$$
\begin{gathered}
\mathrm{H}_{\mathrm{e}}^{\mathrm{b}}=\int_{\mathrm{Ve}} \mathrm{B}^{\mathrm{T}} \cdot \mathrm{D} \cdot \mathrm{B} \cdot \mathrm{dV}+\int_{\mathrm{S}_{2}} \mathrm{~h}_{2} \cdot \mathrm{N}^{\mathrm{T}} \cdot \mathrm{N} \cdot \mathrm{dS}_{2} \\
+\int_{S 1} \mathrm{~h}_{1} \cdot \mathrm{N}^{\mathrm{T}} \cdot \mathrm{N} \cdot \mathrm{d} \mathrm{S}_{1}=\frac{\eta \cdot \mathrm{S} 1}{\mathrm{~L}} \cdot\left[\begin{array}{rr}
1 & -1 \\
-1 & 1
\end{array}\right] \\
+\frac{1}{6} \cdot \mathrm{P} \cdot \mathrm{L} \cdot \mathrm{h}_{2} \cdot\left[\begin{array}{ll}
2 & 1 \\
1 & 2
\end{array}\right]+\mathrm{h}_{1} \cdot \mathrm{S}_{1} \cdot\left[\begin{array}{ll}
1 & 0 \\
0 & 1
\end{array}\right] \\
\mathrm{C}_{\mathrm{e}}{ }^{\mathrm{b}}=\frac{1}{6} \cdot \rho \cdot \mathrm{c} \cdot \mathrm{S}_{1} \cdot \mathrm{L} \cdot\left[\begin{array}{ll}
2 & 1 \\
1 & 2
\end{array}\right],
\end{gathered}
$$

where $V_{e}$ is the element volume; $S_{1}, S_{2}$, and $h_{1}, h_{2}$ are the areas and heat-transfer coefficients of the face and side surfaces of the element, respectively; L is the column length; $\mathrm{P}$ is the perimeter of column cross-section; $\eta, \rho$, and $c$ are the coefficients of heat-conductivity, density, and specific heat capacity of material, respectively.

For elemental annulus, we have Formulae (20) and (21)

$$
\begin{aligned}
\mathrm{H}_{\mathrm{e}}^{\mathrm{r}} & =\frac{2 \pi}{3} \cdot \eta \cdot \frac{\mathrm{R}_{\mathrm{j}}^{3}-\mathrm{R}_{\mathrm{i}}^{3}}{\left(\mathrm{R}_{\mathrm{j}}-\mathrm{R}_{\mathrm{i}}\right)^{2}} \cdot\left[\begin{array}{cc}
1 & -1 \\
-1 & 1
\end{array}\right]+2 \pi \cdot \mathrm{R}_{\mathrm{j}} \cdot \delta \cdot \mathrm{h}_{1} \cdot\left[\begin{array}{ll}
0 & 0 \\
0 & 1
\end{array}\right] \\
& +2 \pi \cdot \mathrm{R}_{\mathrm{i}} \cdot \delta \cdot \mathrm{h}_{2} \cdot\left[\begin{array}{ll}
1 & 0 \\
0 & 0
\end{array}\right]
\end{aligned}
$$

where $R_{j}$ and $R_{i}$ are the element external and internal radiuses; $\delta$ is the element thickness; $h_{1}$ and $h_{2}$ are the heat-transfer coefficients at external and internal surfaces of the element, respectively.

The equation system (16) can be solved using the finite difference method and applying the unconditionally stable central-difference diagram [11]. In order to do this, we replace the derivative in (16) by its approximate finite-difference analogue $\dot{\boldsymbol{T}} \approx\left(T_{\mathrm{i}+1}-T_{\mathrm{i}}\right) / \Delta \mathrm{t}$. Here, $T_{\mathrm{i}}$ and $T_{\mathrm{i}+1}$ are the values of temperature vector in the instants of time $t_{i}$ and $t_{i+1} ; \Delta t$ is the integration step in time. Then, the equation system (16) takes the following form:

$$
\left(\mathrm{H}+\frac{2}{\Delta \mathrm{t}} \cdot \mathrm{C}\right) \cdot\left(T_{\mathrm{i}}+T_{\mathrm{i}+1}\right)=\frac{4}{\Delta \mathrm{t}} \cdot \mathrm{C} \cdot T_{\mathrm{i}}+\left(Q_{\mathrm{i}}+Q_{\mathrm{i}+1}\right)
$$

The system (22) can be solved by step-by-step calculations within the time interval under consideration. At that, for each time step, we determine the matrix $\mathrm{H}$ and the vector $Q$ following the conditions of previous step, and this gives us an opportunity to specify and vary the conditions of uniqueness of solution (heat-transfer coefficients, load, rpm, and lubricant viscosity) in time.

Having the results of temperature analysis, we can start estimation of temperature deformations of SU's elements. Thus, we calculate temperature elongation $\Delta \mathrm{L}$ of each one-dimensional element (column type or radial) using the formula:

$$
\Delta \mathrm{L}=\varepsilon \cdot \mathrm{L} \cdot \Delta \mathrm{T}
$$

where $\mathrm{L}$ is the initial linear dimension of the element under consideration, $\varepsilon$ is the linear expansion coefficient, $\Delta \mathrm{T}$ is the element excessive temperature.

Variations of clearance-tightness in bearings with temperature are caused by the non-uniform heating and differences in linear expansion coefficients of materials of SU's elements. Thus, variation with temperature of the radial clearance-tightness $\Delta_{\mathrm{r}}$ in cylindrical roller bearing can be determined from the balance of displacements:

$$
\Delta_{\mathrm{r}}=\Delta \mathrm{d}_{1}-\Delta \mathrm{d}_{2}+\Delta \mathrm{d}_{3}-\Delta \mathrm{d}_{4}-\Delta \mathrm{d}_{5},
$$

where $\Delta \mathrm{d}_{1}$ is the thermal expansion of housing bush; $\Delta \mathrm{d}_{2}$ is the thermal expansion of spindle's journal; $\Delta \mathrm{d}_{3}$ and $\Delta \mathrm{d}_{4}$ are the thermal expansions of bearing's outer and inner rings, respectively; $\Delta \mathrm{d}_{5}$ is the thermal expansion of rolling bodies (balls or rollers). The temperature deformations $\Delta \mathrm{d}_{1}, \Delta \mathrm{d}_{2}, \Delta \mathrm{d}_{3}, \Delta \mathrm{d}_{4}$, and $\Delta \mathrm{d}_{5}$ can be calculated using the Formula (23).

\subsection{Algorithm of Thermal Analysis}

In Figure 3, we present a flow chart of algorithm for SU thermal analysis, which incorporates the following main procedures. In blocks 1 and 2, we introduce the vector of initial temperature $T_{0}$, the duration of thermal process $\tau$, and the integration time step $\Delta \mathrm{t}$, and calculate the matrices of heat capacity $\mathrm{C}$ and heat conductivity $\mathrm{H}$ of SU by summation of the local matrices.

In block 3, we calculate the vector of SU heat load $Q$ (the power of heat generation in bearings) as a function of the vector of current temperature $T$. The algorithm of bearing temperature analysis is of iteration type, since bearing temperature depends on heat generation in bearings, which, in turn, depends on the temperature via lubricant viscosity, i.e., $Q=Q(v)$ and $v=v(T)$. Heat balance, as we mentioned in i. 2.1, takes place when heat generation equals heat transfer in bearings. In general case, in order to estimate both of these components, we need to introduce some initial temperature. In Figure 4, we present in general the process of successive approximation to the searched bearing's temperature $\mathrm{T}_{\mathrm{B}}$, starting from some initial $\mathrm{T}_{0}$.

In block 4, we solve the equation of SU heat conductivity (16) reduced to the form (22), and determine the

$$
\mathrm{C}_{\mathrm{e}}^{\mathrm{r}}=\frac{\pi \cdot \rho \cdot \mathrm{c}}{30 \cdot \delta^{2}}\left[\begin{array}{cc}
2 R_{j}{ }^{5}-20 R_{j}{ }^{2} R_{i}^{3}+30 R_{j} R_{i}{ }^{4}-12 R_{i}^{5} & 3 R_{j}{ }^{5}-5 R_{j}{ }^{4} R_{i}+5 R_{j} R_{i}^{4}-3 R_{i}^{5} \\
3 R_{j}{ }^{5}-5 R_{j}{ }^{4} R_{i}+5 R_{j} R_{i}{ }^{4}-3 R_{i}^{5} & 12 R_{j}{ }^{5}-30 R_{j}{ }^{4} R_{i}+20 R_{j}{ }^{3} R_{i}{ }^{2}-2 R_{i}^{5}
\end{array}\right]
$$




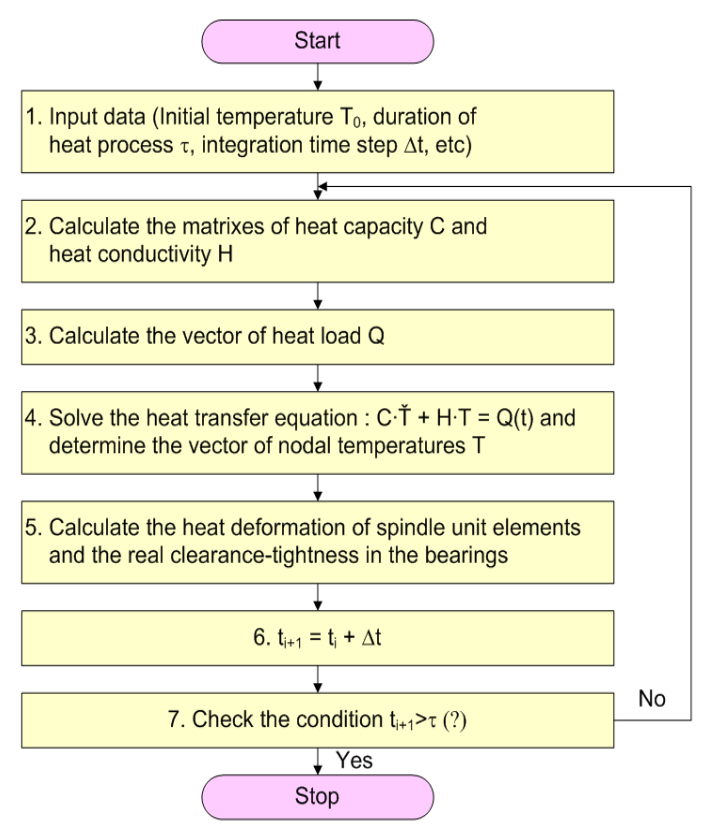

Figure 3. Algorithm diagram of the thermal problem solution.

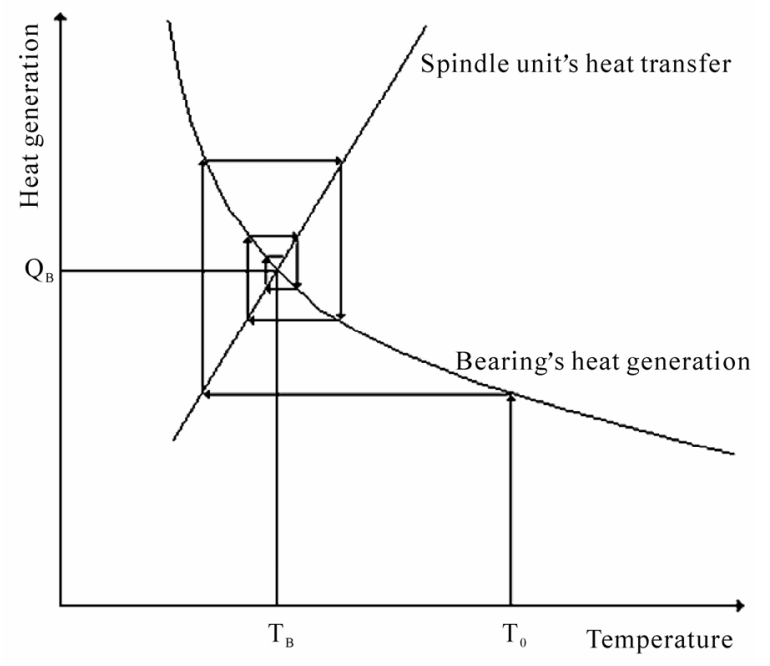

Figure 4. Heat balance in bearings.

vector of node temperatures $T$. Besides, in the cycle, where we determine the temperature in dependence from lubricant viscosity, we check the condition of iteration process conversion. In order to do this, we calculate the absolute values of temperature differences at current and previous steps of iteration for each bearing. We assume that bearing temperature stabilizes, when the temperature difference dose not exceed $0.1{ }^{\circ} \mathrm{C}$. Our experience of computations proves that the estimated temperature stabilizes after 5-7 iterations, if to assume that initial temperature of the bearings is equal to the temperature of the environment.
Then, in block 5, knowing the temperatures $T$, we calculate the temperature deformations of SU's elements and the temperature variations of clearance-tightness in bearings.

In block 6 , we switch to another time interval $t_{i+1}=t_{i}+$ $\Delta \mathrm{t}$. In block 7 , we check, whether the process has reached the given time $\tau$. When this condition will be followed, we stop computations. If not, we recalculate the power of heat generation in SU's bearings for the next time interval in accounting for the values of temperature and clearance-tightness in bearings calculated at previous step, and then, solve again the equation of SU heat conductivity (block 4) and determine the thermal characteristics of SU.

\section{Investigation of Friction and Thermal Properties}

Using the algorithms and software developed, we made the numerical studies of friction and thermal properties of the SUs of grinding and turning machines and compared the results with those obtained in experimental studies. At that, we studied the effect of operation conditions (rpm, axial preload of bearings, external load, conditions of heat transfer from SU's surfaces, type of bearing lubrication, and lubricant viscosity) and checked the validity of mathematical models and software developed.

The experimental study of a grinding machine's SU (Figure 2) we carried out using a rig presented in Figure 5.

The SU was mounted in the air bearing designed for measurements of the bearing friction torque using a thread, one end of which was attached to a strain-gauge transducer, and the other one - to the SU's housing. The strain-gauge transducer signal was amplified by KWS-73 (Hettynger $\mathrm{Co}$ ) and, then, inputted to the spectrum analyser 2031 (B \& K Co.). The spindle was rotated by a belt

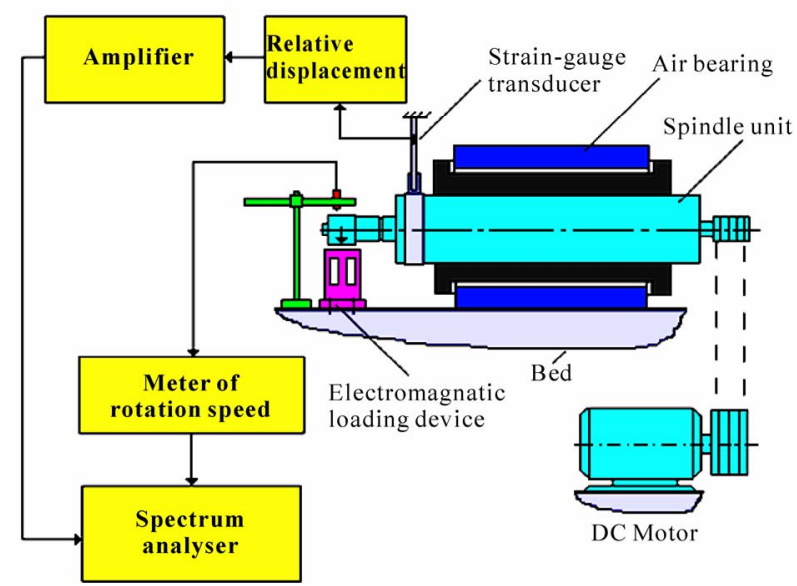

Figure 5. Layout of the experimental rig. 
drive using DC motor. The spindle was constantly radial loaded by a contactless electromagnetic loading device. The SU bearings were axially preloaded with the help of a calibrated spring and a special screw device in the housing to adjust a variable number of working spring coils. The SU temperature we measured using a contact type thermometer (SKF Co.), which provided the accuracy of temperature measurements within $\pm 1{ }^{\circ} \mathrm{C}$ in the temperature band from -40 to $+120^{\circ} \mathrm{C}$. In order to measure the temperature of the front bearing, the SU's housing was drilled through, and the temperature gauge was placed inside the hole. The bearings were lubricated by grease NBU15 (Kluber Co.) having viscosity $13.7 \mathrm{cSt}$ at $40^{\circ} \mathrm{C}$. Before the tests, the $\mathrm{SU}$ was run-in at 5,000 rpm at idle for 4 hours (Figure 6).

From Figure 6(a) it follows that in process of run-in and lubricant mixing, the lubricant viscosity decreases with temperature, and the friction torque decreases approximately in 2.5 times during the first $1.5-2$ hours of

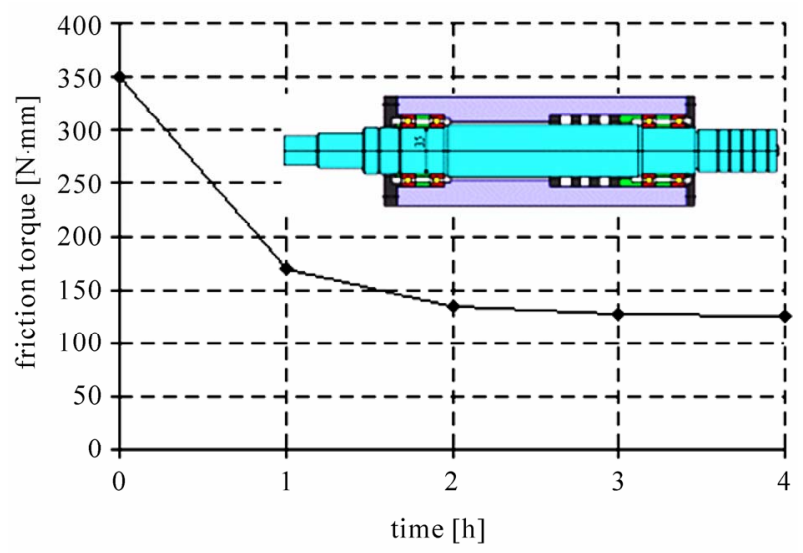

(a)

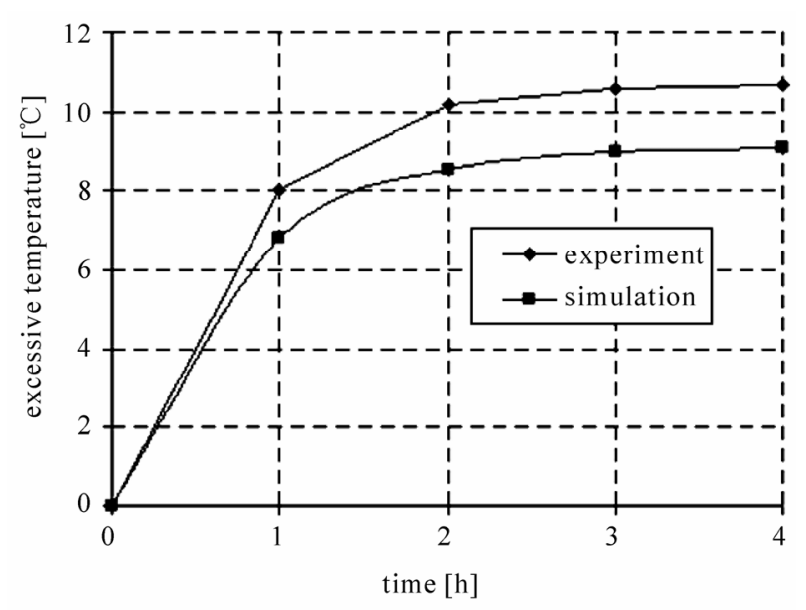

(b)

Figure 6. Aggregate friction torque (a) and temperature (b) in time. (a) friction torque of the bearings; (b) temperature of the front bearing.
SU operation. The bearing temperature stabilization takes place approximately at the same time (Figure 6(b)).

The dependencies of stabilized total friction torque of SU's bearings on rpm and radial load $\mathrm{P}_{\mathrm{r}}$ are presented in Figure 7(a) (for the bearing axial preload $290 \mathrm{~N}$ ).

It follows that at idle $\left(\mathrm{P}_{\mathrm{r}}=0\right)$, an increase of rpm brings to decrease of the torque increment (which is caused, besides the other reasons, by an increase of temperature and decrease of lubricant viscosity), and this does not happen when the spindle is heavy loaded in radial direction $\left(\mathrm{P}_{\mathrm{r}}=800 \mathrm{~N}\right)$. We explain it by the fact that an additional radial loading of high-speed SU brings to loose contacts of a part of bearing's balls with the races, and, thus, to gyroscopic sliding of the balls that increases the friction losses (hydrodynamic component of friction torque). When increasing the bearing preload up to $500 \mathrm{~N}$, the destabilizing effect of radial load on friction torque decreases, because the preload increases

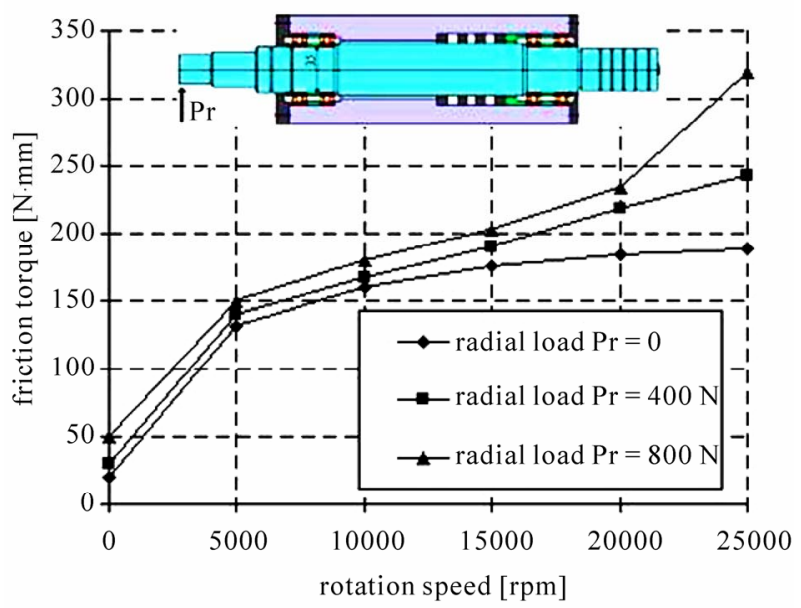

(a)

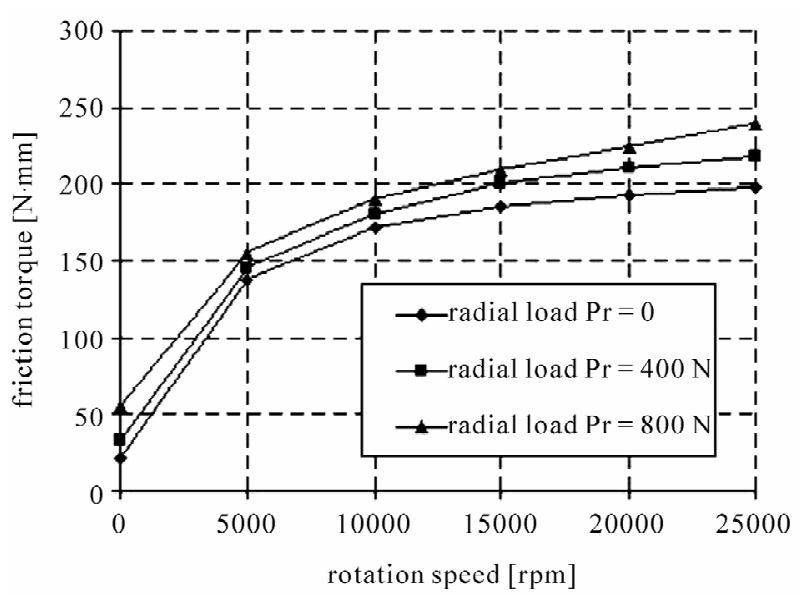

(b)

Figure 7. Experimental aggregate friction torque of the bearings related to $\mathrm{rpm}$. (a) bearing preload $290 \mathrm{~N}$; (b) bearing preload $500 \mathrm{~N}$. 
the loads at balls' contacts and eliminates gyroscopic sliding (Figure 7(b)).

In Figure 8, we present the dependencies of estimated friction torque (Figure 8(a)) and the calculated and measured temperatures of SU's front bearing (Figure 8(b)) on rpm (at idle, i.e., when $\mathrm{P}_{\mathrm{r}}=0$, for the axial preload $290 \mathrm{~N}$ ). We can see that the dependence of bearing temperature on rpm is close to linear. The maximal relative error of bearing temperature calculation at the maximum 25,000 rpm makes $13.5 \%$, and this can be considered to be a satisfactory result in engineering analysis.

From contact-hydrodynamic theory of lubrication [12], it follows that lubricant viscosity and amount, as well as the type of lubrication significantly influence on the friction losses in rolling bearings. That is why improving the parameters and systems of bearing lubrication at present is one of the principle means to increase SU high-speed [8].

In Figure 9(a), we present the results of numerical estimation of the effect of oil viscosity on SU's ball bear-

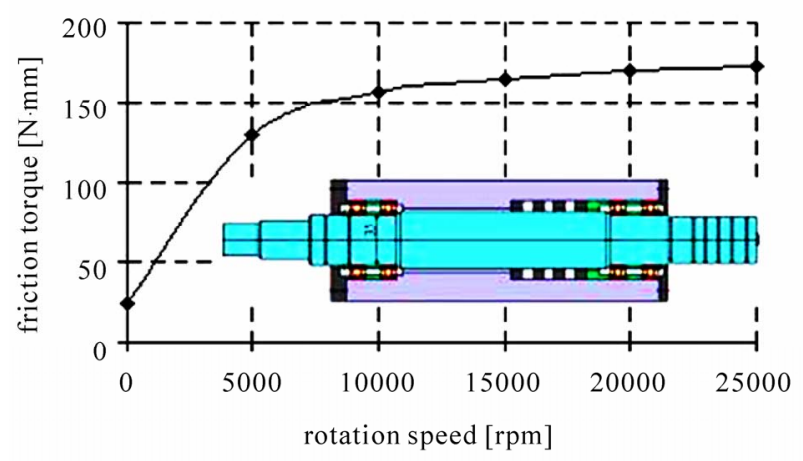

(a)

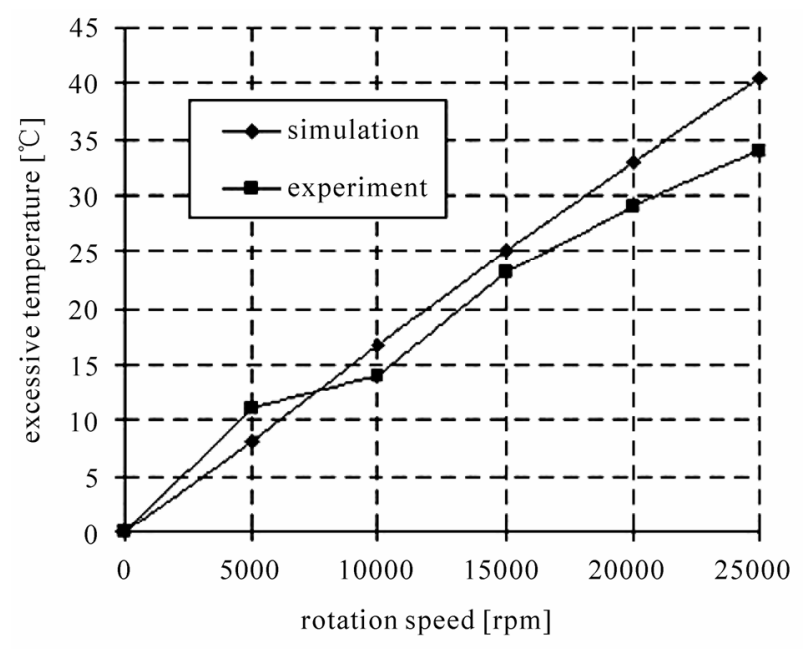

(b)

Figure 8. Aggregate friction torque (a) and temperature (b) related to rpm. (a) friction torque of the bearings; (b) temperature of the front bearing. ing temperature. In Figure 9(b), we present the results of estimation of the effect of lubrication type on the SU's bearing maximum temperature.

From Figure 9 it follows that the effect of lubricant parameters on bearing temperature increases with increase of rpm. Thus, variation in lubricant viscosity brings to more serious variation in temperature at high rpm (see Figure 9(a)). We can see that at 25,000 rpm (Figure 9(b)), SU lubrication with oil-mist (oil-air mixture), reduces the bearing temperature approximately in two times with respect to lubrication with oil. The lubricant volume should be adjusted with rpm to minimize excessive heating. A numerical evaluation of the efficiency of so-called 'minimum' lubrication is presented in [13].

The bearing temperature is greatly influenced by the factor of convective heat transfer from SU's surfaces. Our analysis proves that at low rpm spindle accepts approximately $20-30 \%$ of heat generated in bearings. At high rpm, this figure increases up to $45-55 \%$ because of the increase (in the power 0.7 ) of heat transfer from the open rotating air-cooled surfaces. When making numerical experiments (as shown in Figure 10), we varied the heat-transfer coefficient of SU housing of grinding machine within $20 \mathrm{~W} \cdot\left(\mathrm{m}^{-2} \cdot{ }^{\circ} \mathrm{C}^{-1}\right)$ (that is typical for natural cooling) and $200 \mathrm{~W} \cdot\left(\mathrm{m}^{-2}{ }^{\circ} \mathrm{C}^{-1}\right)$ (that is typical for forced cooling).

The results of analysis show that a significant increase of heat transfer from the housing surface can bring to decrease of bearing temperature by $7-8^{\circ} \mathrm{C}$ at the relatively low rpm $(5,000 \mathrm{rpm})$ and by $20-22^{\circ} \mathrm{C}$ at the high rpm $(20,000 \mathrm{rpm})$. At that, the share of heat transferred by the housing increases up to $80 \%$. A general analysis that we made to study the heat transfer conditions proves high efficiency of this method to bearing temperature decrease.

In SUs with double-row roller bearings, the character of dependence of temperature on rpm can turn to be nonlinear. In the SU assembly, a mounting radial clearance in double-row roller bearings should be provided. At that, when the rpm increases, and the heat generated in bearings increases, as well, a non-uniform heating of the housing and spindle usually brings to a decrease of clearance, which can transform to tightness (Figure 11(a)). When the tightness appears, the friction losses in bearing increase drastically (according to the Formula (13), the dependence has the power 3), and the temperature increases (see Figure 11(b)) too.

The temperature increase with rpm has a dual character. If in the result of heating the clearance does not transform into the tightness, the dependence of temperature on rpm keeps linear, but if the transform takes place, the temperature increases drastically. In Figure 11, we can see that it happens at 5,500 rpm (if the mounting clearance is $5 \mu \mathrm{m})$. The transformation of clearance into 


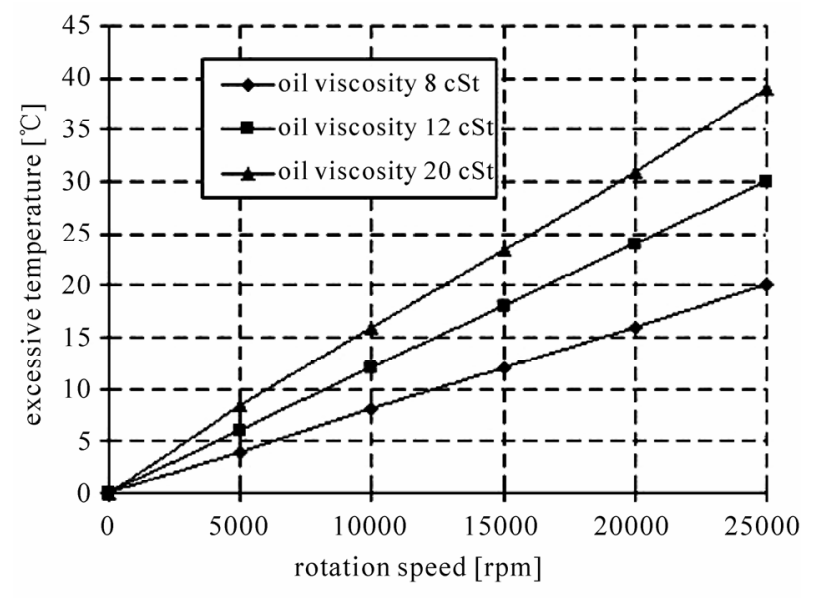

(a)

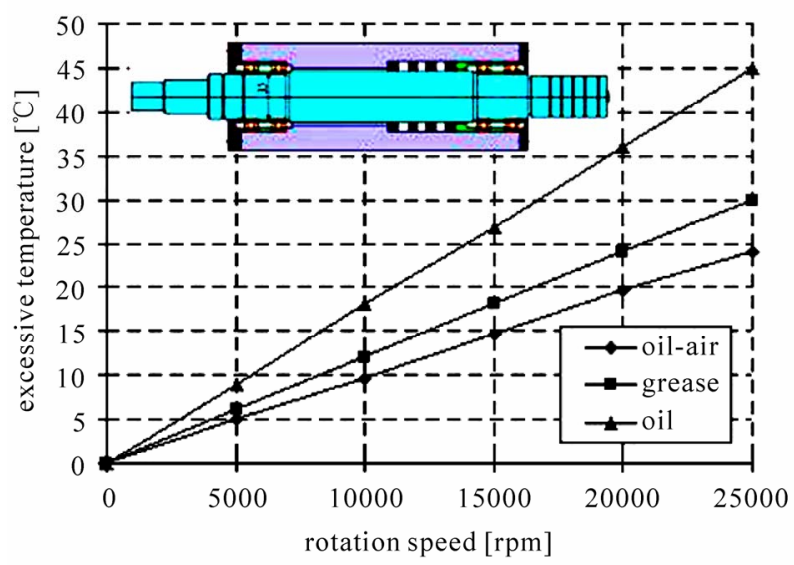

(b)

Figure 9. Temperature of the front bearing related to rpm. (a) effect of lubricant viscosity; (b) effect of lubrication type.

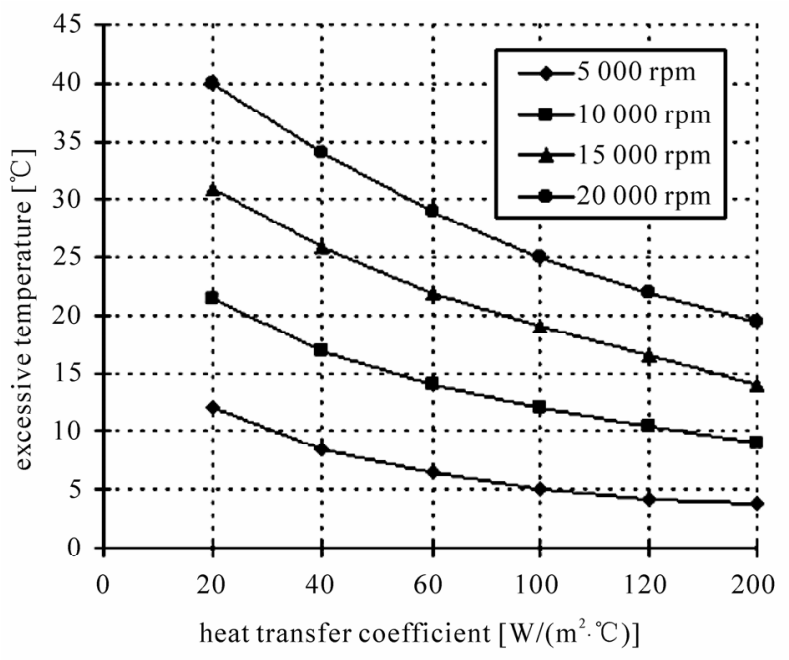

Figure 10. Temperature of the front bearing related to heat transfer coefficient.

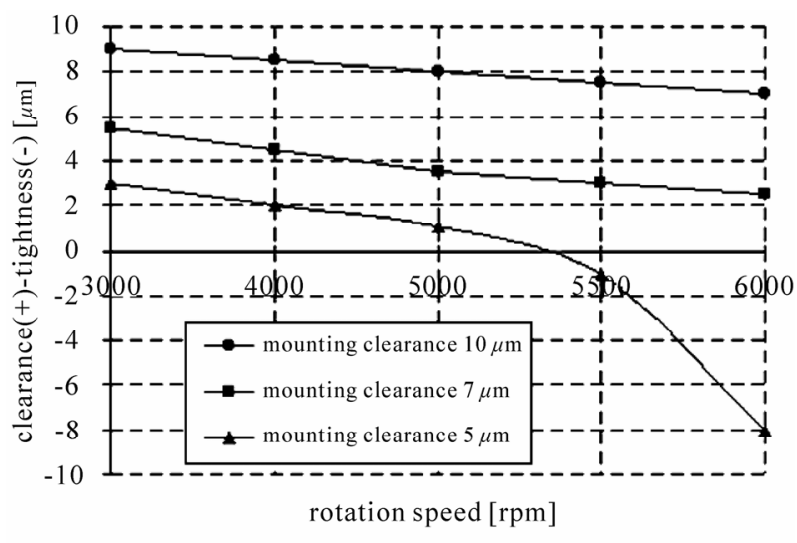

(a)

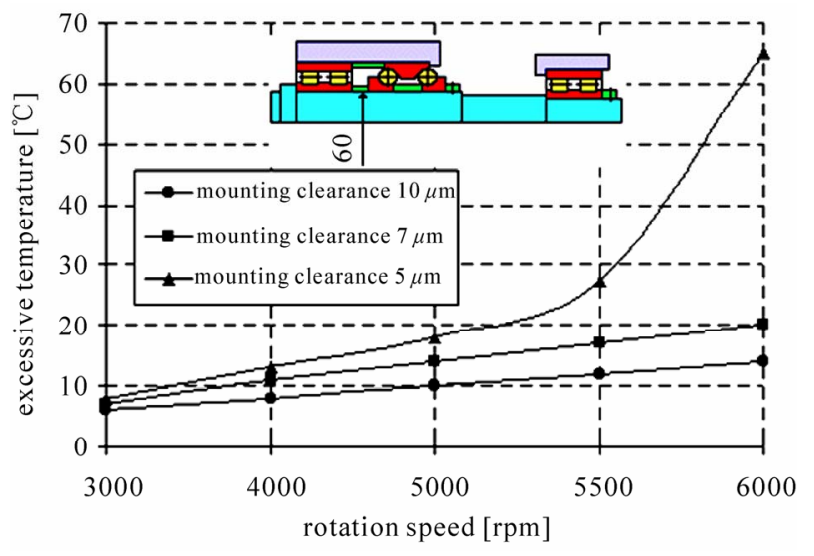

(b)

Figure 11. Real clearance-tightness (a) and temperature (b) related to rpm. (a) clearance-tightness of the front roller bearing; (b) temperature of the front roller bearing.

tightness in SU's bearings, in turn, can bring to the changes of elastic-deformation and dynamic properties of SU (see Figure 1). Thus, the mounting clearance in rolling bearings operating at high rpm should be chosen based on preliminary analysis, and this is of great practical importance. Availability of the SU thermal model even gives us an opportunity to simulate and predict heat 'seizure' in cylindrical roller bearings, which can be caused by a drastic increase of friction losses and temperature in result of the transformation clearancetightness.

\section{Conclusions}

Having a purpose to improve quality of designing of high-speed SUs on rolling bearings, we have developed a SU thermal model, which is one element of a SU complex model. We represented the thermal model as software for express analysis of SUs at the initial stage of designing. The thermal model incorporates a model of heat generation in bearings, a model of heat transfer from 
bearings, and the models for evaluation of temperature and temperature deformations of SU elements. The model is based on application of beam type finite element analytical diagrams of SUs to apply them for solution of problems of statics, dynamics, and heat conduction, which is of a great importance for practical realization of our complex approach to simulation of SUs in designing.

We have made the experimental studies and the numerical estimations of the effect of operation conditions on the friction and thermal properties of SUs of grinding and turning machines. We found out that the dependence of ball bearing temperature on rpm is approximately linear. In the SUs running on double-row roller bearings in the case of small preliminary radial clearance, an increase of rpm can bring to a temperature 'jump' caused by a transformation of clearance into tightness followed by drastic increase of heat generation in the bearing. Under minor external loads, an increase of rpm brings to a decrease of friction torque increment, but this dose not happen under significant external radial loads and low preloads in ball bearings. The effect is caused by unloading a part of balls in the bearing loaded by heavy radial force, and the ball gyroscopic sliding followed by an increase of friction losses. The lubricant parameters and the parameters of SU cooling make stronger effect on bearing temperature when rpm increases. The comparisons of the results of calculations and tests made prove efficiency of the thermal model and its applicability for SU design.

\section{References}

[1] Z. M. Levina, I. G. Gorelik, I. A. Zverev and A. P. Segida, "Computer Analysis of Elastic-Deformation, Dynamic, and Temperature Characteristics of Spindle Units at Designing," Proceedings of Moscow Research Institute of Machine Tools, Russia, 1989, pp. 3-89.
[2] I. A. Zverev and A. V. Push, "Spindle Units: Quality and Reliability at Designing," Moscow State University of Technology Press, Russia, 2000.

[3] A. I. Leontiev, "The Theory of Heat Interchange," High School, Moscow, 1979.

[4] N. A. Spitsin and S. G. Atras, "Friction Losses in Rolling Bearings," Proceedings of Moscow Institute of Bearing Industry, Russia, 1966, pp. 121-130.

[5] A. C. Palmgren, "Grundlage der Waelzlagertechnik," Auflage, Stuttgart, 2000.

[6] A. M. Figatner, "The Effect of Radial Clearance-Tightness of Roller Bearings of Precise Spindle Units," Journal of Machines \& Cutting Tools, Vol. 2, No. 1, 1967, pp. 15-18.

[7] K. G. Gan and L. M. Zaitov, "Dependence of Friction Torque of High-Speed Ball Bearing on Rotation Speed and Axial Preloading," Bulletin of Machine Industry, Vol. 11, No. 5, 1988, pp. 21-23.

[8] V. I. Dzuba, "Effective Lubricant Systems for HighSpeed Spindle Units on Rolling Bearings," Ph.D. Dessertation, Moscow Research Institute of Machine Tools, Moscow, 1985.

[9] K. Brandlein, "Machining Spindle and its Bearings," Proceedings of the Symposium of FAG Company, Moscow Research Institute of Machine Tools, Moscow, 1985, pp. 52-78.

[10] L. J. Segerind, “Applied Finite Element Analysis," John Wiley \& Sons Inc., New York/London/Sydney/Toronto, 1976.

[11] G. Forsythe, M. Malcoln and C. Moler, "Computer Methods for Mathematical Computations," Prentice-Hall, Englewood Cliffs, New Jersy, 1977.

[12] D. S. Kodnir, "Contact Hydrodynamics of Lubrication," Mashinosrtoenie, Moscow, 1979.

[13] A. I. Smirnov, "Optimisation of Lubrication Systems of High-Speed Spindle Units," Proceedings of Moscow Engineering Research Institute, Moscow, 1979, pp. 3-69. 